\title{
Studies Regarding Photovoltaic Solar Energy Potential on Pristol Area, Mehedinti County
}

\author{
Gabriela Demian ${ }^{1, a^{*}}$, Mihai Demian ${ }^{1, b}$ and Lizia Bogdan ${ }^{2, c}$ \\ ${ }^{1}$ University of Craiova, Faculty of Mechanics, Romania \\ ${ }^{2}$ S.C. Pristol Solar Park S.R.L., Romania \\ agabrielademian@yahoo.com, 'bmihaidemian@yahoo.com, ${ }^{\mathrm{b}}$ lizia.bogdan@gmail.com
}

Keywords: photovoltaic solar energy, global horizontal irradiance, direct normal irradiance, diffuse horizontal irradiance.

Abstract. The paper makes an assessment on a long term, of the solar resource, for the location of a photovoltaic solar park in the Pristol, Mehedinti County, Romania. Reference data and the observations in the proximity of the solar park location, were limited, and the analysis was based on a Typical Meteorological Year (TMY), developed based on the Meteonorm dates, to represent the behavior of the solar resource, at the Photovoltaic Solar Park. The level of Global Horizontal Irradiance (GHI), was evaluated as $1376 \mathrm{kWh} / \mathrm{m}^{2} /$ year, in while values for direct normal irradiance (DNI) and diffuse horizontal irradiance (DHI), were $1553 \mathrm{kWh} / \mathrm{m}^{2} /$ year, respectively 606 $\mathrm{kWh} / \mathrm{m}^{2} /$ year, provided for a long-term behavior.

\section{Introduction}

Photovoltaic energy is a real alternative to conventional energy and has the following characteristics: it is a clean energy; low environmental impact; doesn't produce $\mathrm{CO} 2$ emissions or other greenhouse gases, is generated continuously; the solar photovoltaic systems are autonomous.

National energy plan, for Romania, provides as targets, shares of renewable energy in electricity production 35\% in 2015 and 38\% for 2020. Romania has committed to the European Commission that $24 \%$ of total energy consumption in 2020, will come from renewable sources. Energy Regulatory Authority (ANRE) has announced that this target has already been reached on 1 January 2014. Relevance of these studies is confirmed by National Strategy for Energy.

\section{Site analysis}

The "Pristol Solar Park" is a "green-energy" type project, and consists in building a photovoltaic solar park for electricity energy production using solar radiation. The photovoltaic solar park, will have an installed nominal power of about $20 \mathrm{MW}$ and will work at least 1800 hours per year.

Studies have been undertaken on the energetic potential of a photovoltaic solar park, from Pristol Mehedinti area. Analyzed area is in southwestern Romania, $2 \mathrm{~km}$ from the Pristol village and about $58 \mathrm{~km}$ north-east from Bailesti. The location is shown in fig. 1, and the coordinates of the location are given in table 1 .

Table 1 Coordinates of Pristol solar park site

\begin{tabular}{|c|c|c|c|c|}
\hline \multirow{2}{*}{$\begin{array}{c}\text { Pristol Solar } \\
\text { Park }\end{array}$} & \multicolumn{2}{|c|}{ Site coordinates in decimal degrees } & \multirow{2}{*}{ Altitude $(\mathrm{m})$} & Type of land \\
\cline { 2 - 4 } & Latitude $\left({ }^{\circ} \mathrm{N}\right)$ & Longitude $\left({ }^{\circ} \mathrm{E}\right)$ & & \\
\cline { 2 - 5 } & 44.2395 & 22.7053 & 50 & $\begin{array}{c}\text { arid, grassy and } \\
\text { agricultural use }\end{array}$ \\
\hline
\end{tabular}




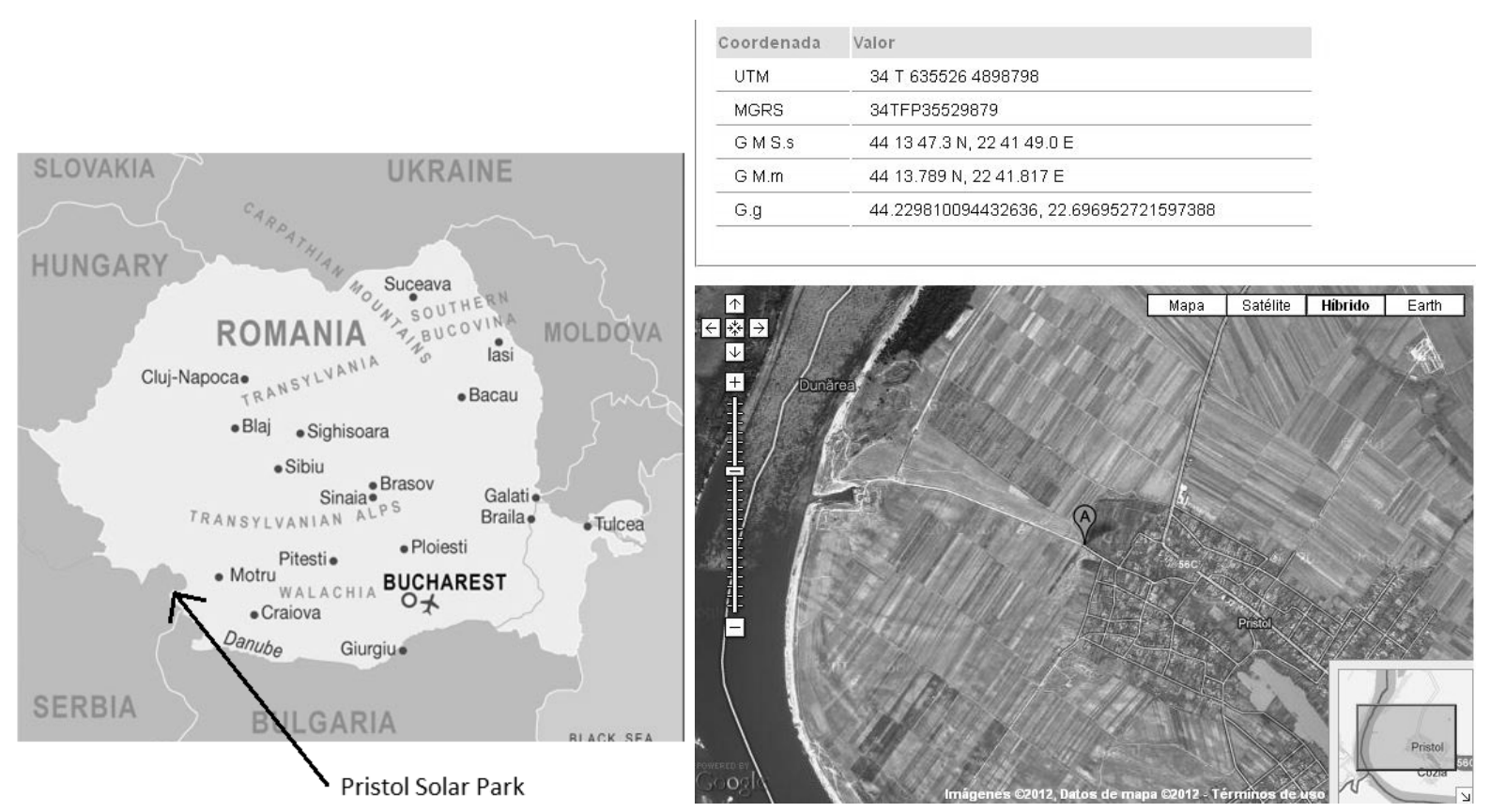

Fig.1 The photovoltaic solar park location

\section{Reference database}

The reference data sources for estimate the long-term solar resource at the project site are:

- HelioClim - HelioClim is a set of databases developed by MINES ParisTech - Armines [1] for solar radiation to different locations based on Meteosat satellite images;

- GeoModel - GeoModel maps provide high-resolution data from the database through SolarGIS weather [2];

- Meteonorm - Meteonorm is reference database weather. For the location analysis were used the time series Meteonorm 8760.

- WRDC - monthly observations of solar radiation records, collected and distributed by WRDC (World Radiation Data Center World Data Center on radiation)

- global databases based on models generated by NASA SSE (National Aeronautics and Space Administration, Surface meteorology and Solar Energy)

- IWEC - 8760 hourly solar database, including the data on solar radiation, generated from databases IWEC (International Weather for Energy Calculations, Weather internationally for energy calculation)

- Network Reference ISH - Meteorological data, for measuring temperature and wind speed, from surface stations belonging to the network of reference stations ISH (National Center radiation data, USA). For this analysis are considered the data from stations Novo Selo and Negotin.

- PVGIS Europe - database of solar radiation, developed by the European Commission, Joint Research Centre.

Analyzed period for solar irradiation was between years 1986 to 2005, and the period for temperature monitoring was between 2000 and 2009.

HelioClim is a set of databases developed by MINES ParisTech - Armines, which provides solar radiation database for different locations in Europe and North Africa, covered by Meteosat satellite. Currently there are available 3 databases; most recently is HC-3 [3]. HC-3 uses the HELIOSAT-2 method, for processing data received from the satellite images and converts them to global radiation data. The components of direct and diffuse irradiation were calculated from these data using algorithms European Solar Radiation Atlas (2000). The satellite data are calibrated using about 29 reference stations global surface. 
GeoModel Maps provides high-resolution data from weather database through SolarGIS C v1.5 [4], including solar radiation, temperature and data about location. The database was developed using a modified version of HELIOSAT-2 method, created from Meteosat Second Generation Satellite database and atmospheric data using own algorithms, including inputs and improvements proposed by Perez [5], Durr and Zelenka [6], Cebecauer [7,8]. The model has been validated using high quality data recorded on surface throughout Europe and North Africa. The databases are available with a spatial resolution of $250 \mathrm{~m}$ (developed from data on a $5 \mathrm{~km}$ using SRTM-3 Digital Elevation Model); the temporal frequency is 15-minutes. For this study, were used, the countryspecific maps of solar radiation developed and published on GeoModel through its website.

Meteonorm is a reference meteorological database, developed for solar applications and systems design in any location. The database incorporates weather data from more than 8,000 weather stations, including over 1,500 measurements of solar radiation with extensive records periods. Meteonorm uses various models of solar radiation and meteorological models that allow interpolation and data collection for any specific location. Accuracy of data series depends on the number of measuring stations near location. Data can be exported to over 30 different formats, compatible with a variety of software packages. For the location analysis were used the time series Meteonorm 8760.

WRDC-WRDC (World Radiation Data Center) serves as a repository of solar radiation data, measured at any location worldwide. It is maintained by the Russian Federal Service for Hydrometeorology and Environmental Monitoring of the World Meteorological Organization (WMO); the data are collected in more than 1,000 sites available through an online data management service available. Monthly radiation data available in the network WRDC stations were for the period between 1964 and 1993.

NASA SSE - NASA played a role in the development of meteorological records on surface and development of solar database, geared specifically to the design of renewable energy systems, contributing to the commercial application of this type of data.

There are monthly averages data of satellite measurements available for the period 1983-1993 for any terrestrial site.

IWEC International Weather for Energy Calculations - IWEC The IEWC are the result of ASHRAE Research Project 1015 by Numerical Logics and Bodycote Materials Testing Canada, who developed meteorological data files measures applicable in simulation programs for building energy calculation for 227 locations outside the United States and Canada. Data files come from 18 years of hourly meteorological DATSAV3 obtained from U.S. National Climatic Data Center. The weather data is supplemented by solar radiations estimated on an hourly basis from earth-sun geometry and hourly weather elements, particularly cloud amount information. International Weather for Energy Calculation (IWEC) files, which cover 3,012 worldwide locations outside the United States and Canada, are now available for individual purchase.

Reference Network ISH-Through ISH database of NCDC (National Radiation Data Center, U.S.) global data are available surface meteorological stations. Since 1998, National Radiation Data Center the Air Force and the U.S. Navy began to collect data from surface observations, in the five years since, were published versions incorporating multiple successive improvements of the quality of available data. Hourly synoptic observations over 20,000 stations worldwide, of which 11,000 are still active today, are combined in a database in a single integrated data model. Measures include wind speed and direction, dry bulb temperature, wind, cloud cover data, dew point, precipitation, snow depth and other meteorological parameters.

\section{Estimating solar resource, for a long-term. Developing Typical Meteorological Year (TMY)}

To accurately characterize the solar resource potential, and define the daily and seasonal distributions of databases, were developed Typical Meteorological Year (TMY) specific to the project site. The TMY data base is defined as a series of frecuency hourly data of annual long-term behavior of radiation and meteorological parameters (GHI, DNI, DHI, ambient temperature and 
wind speed) [9]. In general, in developing of the TMY are used preferably historical data bases for extended periods of time when these records are available. Given the limited availability of records in the region, the number of hourly data Meteonorm is considered the most suitable to be used as a historical database in this analysis.

The long-term annual values, of parameters GHI, DNI and DHI, (tables 2-4), (figs. 2-7) (global horizontal radiation, normal direct and horizontal diffuse radiation components) were estimated at $1376 \mathrm{kWh} / \mathrm{m}^{2} /$ year, $1553 \mathrm{kWh} / \mathrm{m}^{2} /$ year and respectively, $606 \mathrm{kWh} / \mathrm{m}^{2} /$ year. Table 3 provides a comparison between the values obtained for the project and the results presented by other models of references available. The hourly values of temperature and wind speed were obtained from the measurement station of Negotin $(13 \mathrm{Km}$ distance Pristol), obtained from the surface station network ISH.

Table 2 Annual estimates of radiation and meteorological parameters of the site

\begin{tabular}{|c|c|}
\hline Radiation & Estimated annual radiation $\left(\mathrm{kWh} / \mathrm{m}^{2} /\right.$ year $)$ \\
\hline Global Horizontal Irradiance $(\mathrm{GHI})$ & 1376 \\
\hline Direct normal irradiance (DNI) & 1553 \\
\hline Diffuse horizontal irradiance (DHI) & 606 \\
\hline \hline Temperature yearly average & $12.6^{\circ} \mathrm{C}$ \\
\hline Wind speed yearly average & $1.9 \mathrm{~m} / \mathrm{s}$ \\
\hline
\end{tabular}

Table 3 Annual average of radiation ( $\mathrm{kWh} / \mathrm{m}^{2} /$ year) according to different data models

\begin{tabular}{|c|c|c|c|}
\hline Site & GHI $\left(\mathrm{kWh} / \mathrm{m}^{2} /\right.$ year $)$ & $\mathrm{DNI}\left(\mathrm{kWh} / \mathrm{m}^{2} /\right.$ year $)$ & DHI $\left(\mathrm{kWh} / \mathrm{m}^{2} /\right.$ year $)$ \\
\hline Pristol Solar Park Site & 1376 & 1553 & 606 \\
\hline Model Satellite HelioClim & 1534 & 1763 & 474 \\
\hline Model NASA SSE & 1294 & 1435 & 546 \\
\hline IWEC TMY Data Set & 1373 & 1163 & 649 \\
\hline
\end{tabular}

Table 4 Yearly solar radiation table (Meteonorm database)

\begin{tabular}{|l|c|c|c|c|c|}
\hline Yearly solar radiation & $\mathrm{GHI}$ & $\mathrm{DNI}$ & $\mathrm{DHI}$ & $\begin{array}{c}\text { Monthly mean of } \\
\text { air temperature } \\
\mathrm{Ta}\left({ }^{0} \mathrm{C}\right)\end{array}$ & $\begin{array}{c}\text { Wind } \\
\text { speed } \\
(\mathrm{m} / \mathrm{s})\end{array}$ \\
\hline January & $\mathrm{kWh} / \mathrm{m}^{2}$ & $\mathrm{kWh} / \mathrm{m}^{2}$ & $\mathrm{kWh} / \mathrm{m}^{2}$ & 0.4 & 2.1 \\
\hline February & 45 & 68 & 18 & 2.7 & 2.2 \\
\hline March & 67 & 90 & 28 & 7.5 & 2.3 \\
\hline April & 104 & 125 & 45 & 12.9 & 1.8 \\
\hline May & 143 & 157 & 67 & 18.5 & 1.7 \\
\hline June & 177 & 183 & 82 & 21.7 & 2 \\
\hline July & 187 & 187 & 72 & 24.1 & 2 \\
\hline August & 202 & 206 & 74 & 24 & 1.8 \\
\hline September & 163 & 174 & 72 & 18 & 1.7 \\
\hline October & 120 & 136 & 53 & 12.8 & 1.6 \\
\hline November & 81 & 100 & 44 & 7 & 1.9 \\
\hline December & 50 & 69 & 27 & 1.5 & 1.6 \\
\hline Year & 40 & 59 & 21 & 12.6 & 1.9 \\
\hline
\end{tabular}




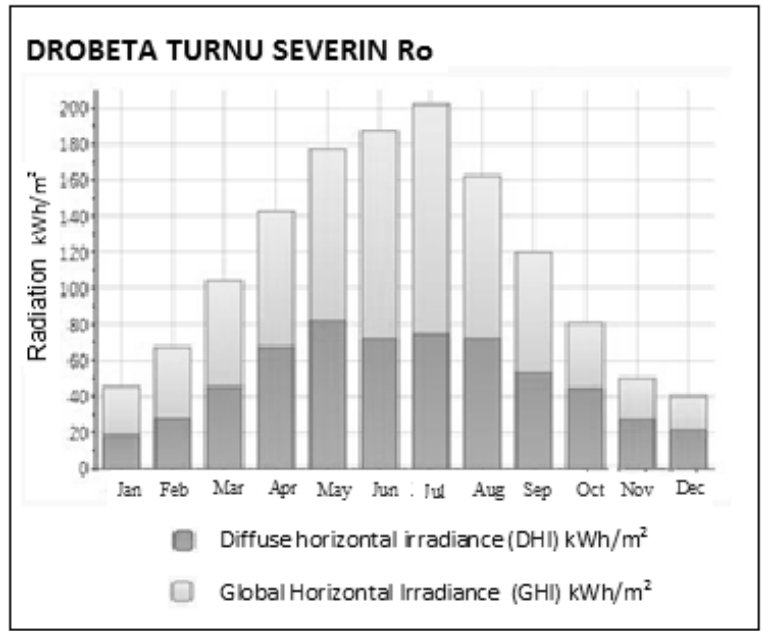

Fig.2 Radiation

(Meteonorm database)

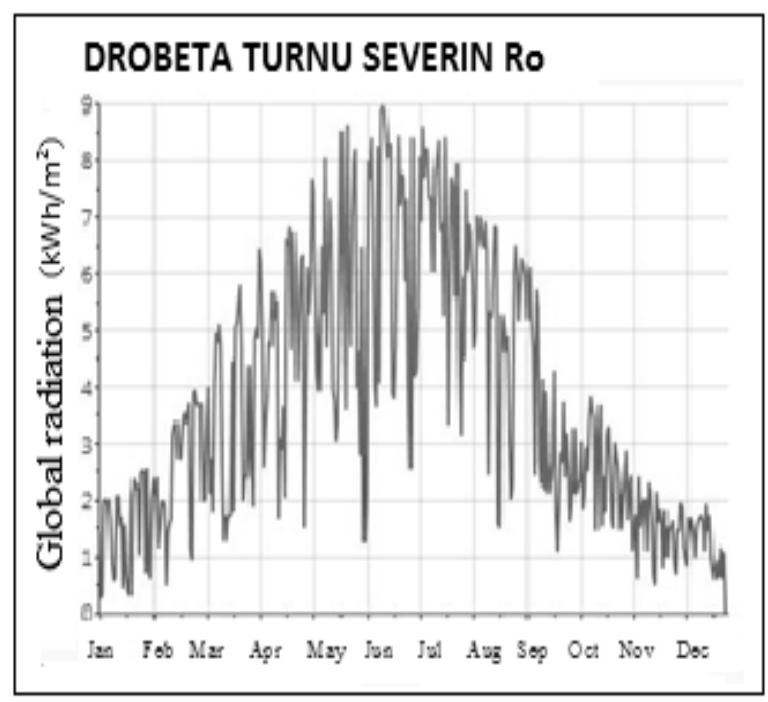

Fig.4 Daily global radiation (Meteonorm database)

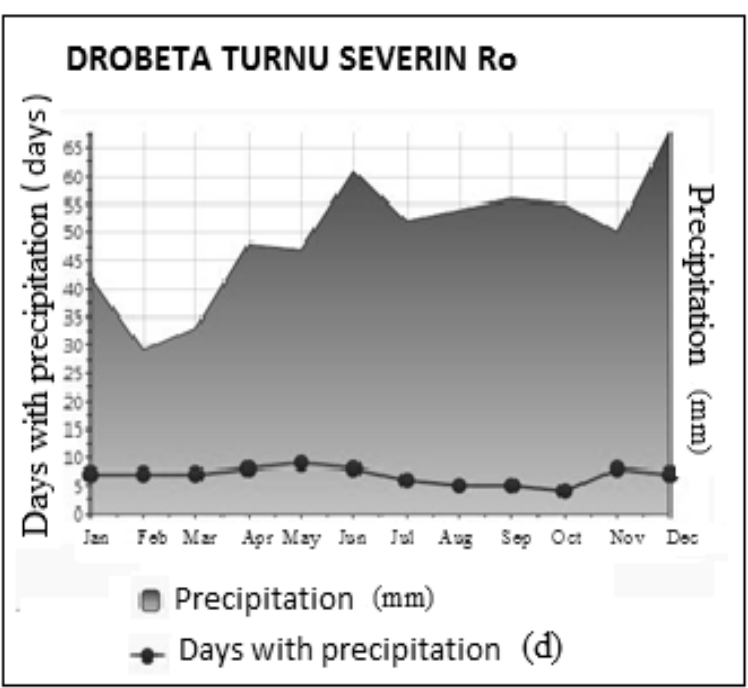

Fig. 6 Precipitation (Meteonorm database)

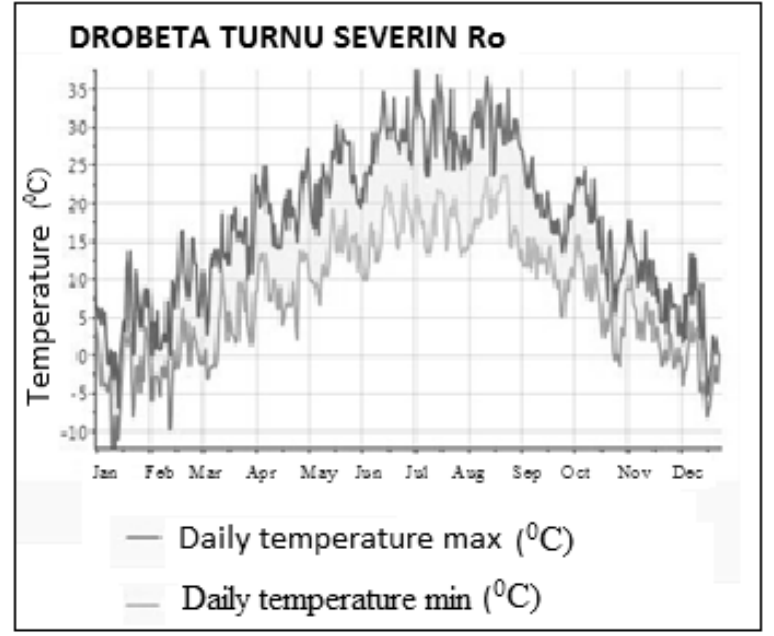

Fig.3 Daily temperature (Meteonorm database)

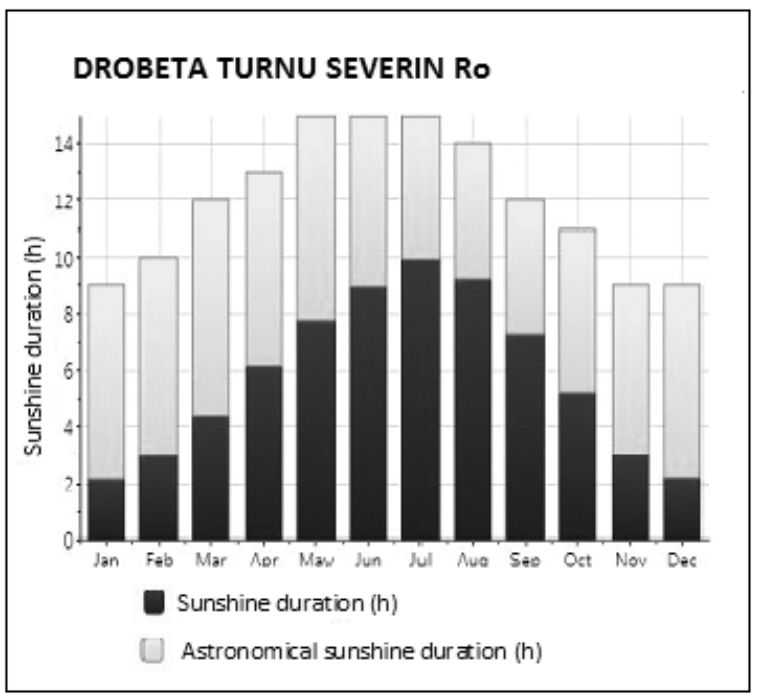

Fig.5 Sunshine duration (Meteonorm database)

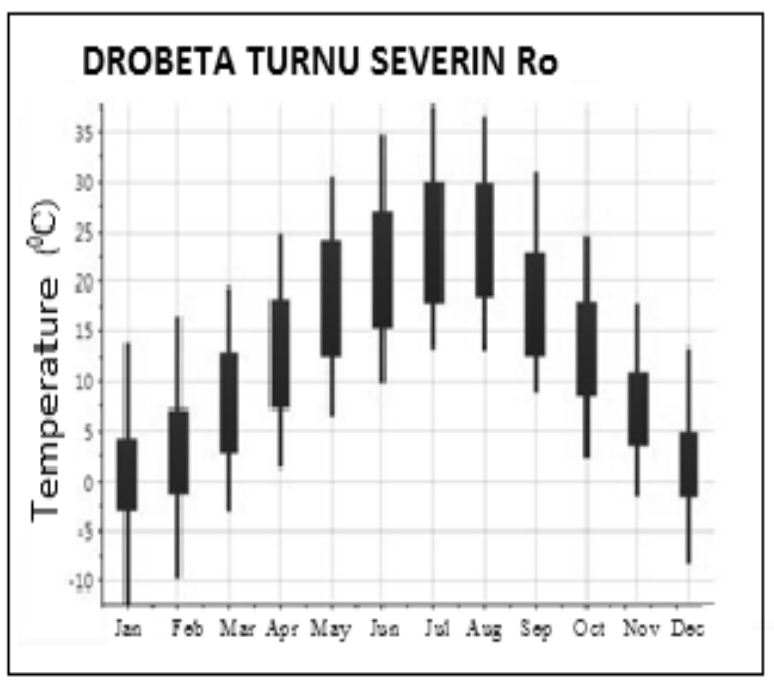

Fig. 7 Temperature (Meteonorm database) 
To quantify the quality of data from long-term use, there has been estimated the uncertainty of radiation results previously obtained; it has been considered the accuracy of the measurement, the interannual variability of the resource, the registration period and the space variability. For this assessment, the uncertainty is defined as the standard error of a normal probability distribution.

Measurement Accuracy - This low uncertainty value indicates the accuracy of the data used to estimate the long-term solar resource obtained from measurements or calculations, to estimate the long-term use. The elements taken into consideration in assessing this factor includes the types of sensors used in records, the stability of the sensors, the on-site preventive maintenance and calibration of the sensors in cases of in situ measurements. In the case of database based on models, uncertainty focuses on the uncertainty associated with the models, the adjustments made on the resulting data model, model comparisons with available in situ measurements and experience in evaluating different models. Based on the experience gained in projects under similar conditions, the measurement associated with the accuracy of measurement is quantified in a $6.0 \%$

Interannual variability of the resource - This uncertainty value indicates the natural differences in the solar resource from one year to another. The interannual variability is calculated from several years of high quality reference data and varies by region. The effect of the local climate can cause considerable variation in this component sites being located a short distance. Based on the reference data available in this region, the uncertainty associated with the interannual variability of radiation was estimated at $3.2 \%$

Representativeness of the monitored period - This uncertainty value affects to what extent the historical behavior represent the period of data available long term. For the evaluation of this uncertainty is considered the level of correlation between in-situ measurements and reference data, registration periods, the reliability of site records and interannual variability. The valuation assumes that the annual average varies randomly according to a normal distribution, for which the margin of error varies inversely with the square root of the record number of years. Based on the number of years of Meteonorm record, has been assigned to these dates an uncertainty value of $0.7 \%$.

Spatial variability - This uncertainty value affects the spatial variation of the solar resource throughout the region of interest. Since the solar estimation is based on point focused measurement focused on the geographical coordinates of the project, it is unnecessary in this case to apply a value of uncertainty associated with the spatial variability component. The effect of spatial variability in estimates energy is related to the total area of the project, and could recommended its consideration on estimated level of production.

Individual values and global uncertainty GHI component are shown in Table 5. The overall uncertainty component or combined uncertainty of GHI component to the project site has been estimated at a value of about $8.3 \%$, corresponding to $114 \mathrm{kWh} / \mathrm{m}^{2} /$ year.

Table 5 The uncertainty values

\begin{tabular}{|c|c|c|}
\hline \multirow{2}{*}{ Uncertainity values } & \multicolumn{2}{|c|}{ GHI } \\
\cline { 2 - 3 } & $\%$ & $\left(\mathrm{kWh} / \mathrm{m}^{2} /\right.$ year $)$ \\
\hline Measurement Accuracy & 6.0 & 82.56 \\
\hline Interannual variability of the resource & 3.2 & 44.03 \\
\hline Representativeness of the monitored period & 0.7 & 9.63 \\
\hline Global uncertainity & 8.3 & 114.2 \\
\hline
\end{tabular}

\section{Conclusions}

The paper makes an assessment of the long term solar resource for the location of a photovoltaic solar park in the Pristol, Mehedinti County, Romania. Reference data and observations in the proximity of the solar park location were limited, and the analysis was based on a Typical Meteorological Year (TMY) developed by Meteonorm, to represent the behavior of the solar 
resource at the site of photovoltaic solar park. The annual irradiation values represented in the TMY (Typical Meteorological Year) database reflect long term behavior, excluding extreme conditions. The level of Global Horizontal Irradiance (GHI) was evaluated as $1376 \mathrm{kWh} / \mathrm{m}^{2} /$ year, while values for direct normal irradiance (DNI) and diffuse horizontal irradiance (DHI), the resulting values were $1553 \mathrm{kWh} / \mathrm{m}^{2} /$ year and $606 \mathrm{kWh} / \mathrm{m}^{2} /$ year, respectively, provided for long-term behavior.

The overall uncertainty level of the Global Horizontal Irradiance is $114.2 \mathrm{kWh} / \mathrm{m}^{2} /$ year (GHI), which is equivalent to a percentage of $8.3 \%$, corresponding to a result of estimation of the levels of at least $1262 \mathrm{kWh} / \mathrm{m}^{2} /$ year (GHI) for a confidence level of $92 \%$.

\section{References}

[1] http://www.ensmp.fr/Accueil/

[2] http://geomodelsolar.eu/maps/

[3] Rigollier, C., Lefevre, M., Wald, L., 2004, The method Heliosat-2 for deriving shortwave solar radiation from satellite images, Solar Energy, 77(2), 159-169, 2004.

[4] http://solargis.info/

[5] Perez, R., Ineichen, P., Moore, K., Kmiecik, M., Chain, C., George, R., Vignola, F., A new operational model for satellite-derived irradiances: description and validation, Solar Energy Vol. 73, No. 5, pp. 307-317, 2002.

[6] Durr, B. and A. Zelenka, 2009. Deriving overall surface irradiance over the Alpine region from METEOSAT Second Generation data by supplementing the HELIOSAT method, International Journal of Remote Sensing, vol. 30, no. 22, pp. 5821-5841.

[7] Cebecauer, T., Suri, M., Perez, R., High performance MSG satellite model for operational solar energy applications, ASES SOLAR 2010 Conference, Phoenix, Arizona USA.

[8] Cebecauer, T., Suri, M., Accuracy Improvements of Satellite-Derived Solar Resource Based on Gems Re-analysis Aerosols, SolarPACES Conference, Perpignan, France, in September. 2010.

[9] http:/geomodelsolar.eu/data/typical-meteorological-year. 